\title{
Analysis of Transient Dynamic Response of Two Nearby Micro-Grids under Three Different Control Strategies
}

\author{
Rashad M. Kamel, Aymen Chaouachi, Ken Nagasaka
}

Environmental Energy Engineering, Department of Electronics \& Information Engineering, Tokyo University of Agriculture and Technology, Tokyo, Japan.

Email:__m_kamel@yahoo.com, a.chaouachi@gmail.com, bahman@cc.tuat.ac.jp

Received October 11 $1^{\text {th }}, 2010$; revised November 20 $0^{\text {th }}, 2010$; accepted December $10^{\text {th }}, 2010$.

\begin{abstract}
The need of reducing $\mathrm{CO}_{2}$ emissions in electricity generation field for solving global warming problems have led to increase the interest in Micro-Grid (MG) especially the one which included renewable sources. MG normally operates in normal interconnected mode and connects with the main grid. When a large disturbance happens in main grid, $M G$ transfer to islanding mode. This paper deals with connecting two nearby Micro-Grids to enhance transient dynamic response of the two MGs after isolated from the main grid. Three cases are investigated. The first case discussed the dynamic response of the two MGs when there is no tie line connection between the two MGs after islanding. Second case, studied the dynamic performance of the two Micro-Grids when there is a private line connects the two MGs after islanding from main grid, while the third case deals with two interconnected MGs (after islanding) and automatic generation control ( $A G C$ ) applied upon each $M G$ to return the frequency to its nominal value and control the tie line power to be with its scheduled value. Results proofed that when two nearby MGs are connected by private line after islanding from the main grid occurs, dynamic response of the two MGs improved well.
\end{abstract}

Keywords: Micro-Grid, Islanding, Dynamic Response, Tie Line, Nearby MGs and Automatic Generation Control

\section{Introduction}

Economic, technology and environmental incentives are changing the face of electricity generation and transmission. The need of reducing $\mathrm{CO}_{2}$ emissions in the electricity generation field, recent technological developments in micro generation domain in addition to electricity business restructuring are the main factors responsible for the growing interest in the use of micro generations [1,2]. Energy investors and utility operators are attracted to the MG role and associated industry for the following foreseen opportunities [3]:

- Distributed generators (DGs) installed inside $\mathrm{MG}$ can be fueled by locally available renewable and alternative mix of fuel sources. Greater independency from importing petroleum fuel can be achieved by incorporating MG that is powered by various fuel sources.

- MG can support future increase in demand without investment in the expansion of existing distribution network by installing the MG very close to the new load centre.

- MG can be used in reducing intermittent and peak supply burdens on utilities grid by injecting power during peak periods.

- MG could contribute to decreasing the vulnerability of the electric distribution system to external threats and hidden undetected faults that may cause wide scale blackout by feeding power to the sensitive infrastructure.

In fact the connection of small generation units (micro sources) with power rating less than a few tens of kilowatts to low voltage (LV) networks potentially increases the reliability to final consumers and brings additional benefits for global system operation and planning, namely, regarding investment reduction for future grid reinforcement and expansion [4]. In this context, a MG can be defined as a low voltage network (e.g. a small urban area, a shopping center, or an industrial park) plus its loads and several small modular generation systems connected to it, providing both power and heat to local loads. The MG is intended to operate in the following two different operating conditions:

- Normal Interconnected Mode: MG is connected to a main grid (distribution network), either being supplied by it or injecting some amount of power 
into the main system.

- Islanding Mode: MG operates autonomously, in a similar way to physical islands, when the disconnection from the upstream distribution network occurs.

The development of MG can contribute to the reduction of emissions and the mitigation of climate changes; this is because available and currently developing technologies for distributed generation units are based on renewable sources and micro sources that are characterized by very low emissions [5]. The new micro sources technologies (e.g. micro gas turbines, fuel cells, photovoltaic panels and several kinds of wind turbines) used in MG are not suitable for supplying energy to MG directly. They have to be interfaced with the MG through an inverter. Thus, the use of power electronic interfaces in the MG leads to a series of challenges in the design and operation of the MG [6]. Technical challenges associated with the operation and control of MG are immense. Ensuring stable operation during network disturbances, maintaining stability and power quality during the islanding mode of operation requires the development of sophisticated control strategies for MG's inverters in order to provide stable frequency and voltage in the presence of arbitrarily varying loads.

\subsection{General Overview}

Reference [4] described and evaluates the feasibility of control strategy to be adopted for the operation of the MG when it becomes isolated. Reference [5] studied the MG during both connected and islanded modes of operations. Reference [7] investigated preplanned switching events and fault events that lead to islanding of the MG. The feasibility of the MG islanding mode concept was laboratory tested in a prototype installed in National Technical University of Athens (NTUA) which compromises a photovoltaic (PV) panel, battery storage, loads and a controlled interconnection to LV grid [8]. In [9] and [10], the behavior of micro sources connected to distribution networks has been addressed.

All the previous mentioned references besides all other works available in the literature dealt with dynamic response of one MG only. The next few years will see integration of many MGs inside the same distribution network. At that time, if the nearby MGs are connected with each other by a private line (following fault or high disturbance occurrence in the distribution network), the transient dynamic response of all interconnected MGs will highly improved. This paper dealt with the investigation of transient dynamic response of two interconnected MGs after islanding from the distribution network occurs. To deals with the proposed study, the following three issues are described.
1) Investigating the transient dynamic response of two MGs subsequent islanding occurrence from the main grid if the two MGs are not interconnected with each other.

2) Investigating the transient dynamic response of the two MGs subsequent islanding occurrence from the main grid and the two MGs are connected with each other through a private line.

3) Third case is close to the second case in addition to automatic generation control (AGC) is applied inside each $M G$ to return the frequency to the nominal value and control the tie line power to its scheduled value.

The rest of the paper is organized as follow. Section 2 describes architecture of the two investigated MGs and the conditions which may lead to transfer the two MGs to the islanding mode. Section 3 presents a brief description of all micro sources installed inside the two MGs. Section 4 describes three control scenarios proposed for improvement the dynamic performance of adjacent MGs. Results and discussion are presented by Section 5. Conclusions are exist in Section 6.

\section{Architecture of the Developed Two MGs System}

Figure 1 shows architecture of the developed two MGs system. System consists of two MGs, each MG connected to the main grid (distribution network) through separate transformer $\left(\mathrm{T}_{1}\right.$ and $\left.\mathrm{T}_{2}\right)$. The two MGs have the same structure but with different micro sources rating and loading. Each MG comprises low voltage network, loads, both controllable and non controllable micro sources and storage device (flywheel). Controllable micro sources are the micro sources which can control their output power like micro turbine and fuel cell, while the non controllable micro sources are the micro sources which their output depends on weather conditions like wind turbines and photovoltaic panels. As shown in Figure 1 each MG consists of 7 buses. Flywheel (storage device) is connected to bus 1 . Wind generation system is located at bus 2. Two photovoltaic panels with different rating are connected to buses 4 and 5. Single Shaft Micro Turbine (SSMT) is connected to bus 6 . Bus 7 is provided with Solid Oxide Fuel Cell (SOFC). Rating of all micro sources and loads in two MGs are shown in the figure. All micro sources in the two MGs are interfaced to the MG through inverters except the wind generation system directly coupled. As shown in the figure, in steady state the two MGs are connected to the distribution network (main grid). If fault occurs in main grid as shown in the figure, the two MGs will be isolated from the main grid as soon as possible by $\mathrm{CB}_{1}$ and $\mathrm{CB}_{2}$, while $\mathrm{CB}_{3}$ connects the two MGs with each other. As we will see in the results, this proposed strategy has large effect for enhancement the transient dynamic response of the two MGs. 


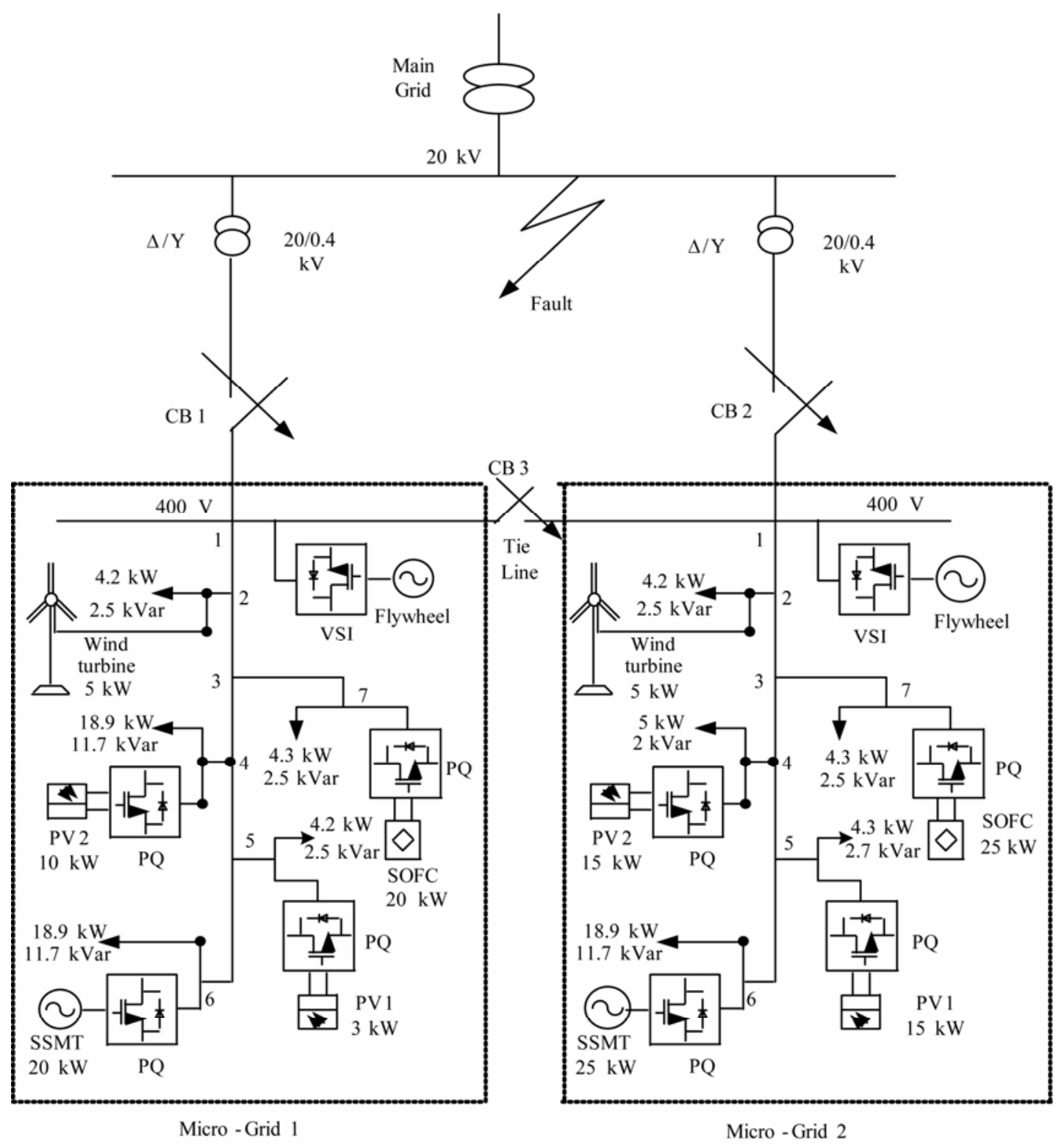

Figure 1. Architecture of the developed two MGs system.

\section{Dynamic Modeling of MG's Components}

All MG's components are modeled in detail using Matlab ${ }^{\circledR}$ Simulink ${ }^{\circledR}$ environment. Detailed standalone models for inverter with different control strategies, SSMT, SOFC, wind generation system and photovoltaic panel models are developed in our previous work and can be found in references [11,12]. All models developed in references [11,12] are based on description and equations presented by references [13-15]. Here we will briefly describe about the inverter control strategies used in this paper and storage devices (flywheel) modeling beside three control strategies adopted to improve the performance of the two MGs.

\subsection{Inverter Modeling}

Inverter plays a vital role in the system which interference of micro sources with MG. Two kinds of control strategies are developed in this study to operate the inverter.

1) PQ Inverter Control: This type of inverter is used to inject a certain active and reactive power set-value. This type of inverter is used to interface SSMT, SOFC and the two photovoltaic panels. The basic structure of the inverter PQ controller is shown in Figure 2. $P_{\text {ref }}$ in Figure $\mathbf{2}$ represents active power produced by the micro source which interfaced to the MG by this inverter. $\mathrm{Q}_{\text {ref }}$ represents amount of reactive power injected to or absorbed 
from the MG at inverter's bus.

2) Voltage Source Inverter (VSI) Control: This inverter is controlled to "feed" the load with predefined values of voltage and frequency. Depending on the load, the VSI real and reactive power is defined. VSI is used to interface storage device (flywheel) to the MG and represent reference bus (slack bus) for each MG during islanding mode. VSI emulates the behavior of synchronous machine, thus controlling voltage and frequency on the AC system. VSI acts as a voltage source, with the magnitude and frequency of the output voltage controlled through droops, as described in the following equation:

$$
\begin{aligned}
& f=f_{o}-k_{P} * P \\
& V=V_{o}-k_{Q} * Q
\end{aligned}
$$

Where, $P$ and $Q$ are the inverter active and reactive output power, $k_{P}$ and $k_{Q}$ are the droop slopes (positive quantities), and $f_{o}$ and $V_{o}$ are the idle values of the frequency and voltages (nominal frequency and nominal voltage).

A three-phase model of a VSI implementing the droop concepts described by Equation (1) was developed as shown in Figure 3. In this model amount of active and reactive power injected to or absorbed from $\mathrm{MG}$ will control the voltage and frequency of the MG (like synchronous generator).

\subsection{Storage Devices Modeling}

Due to the large time constants of responses of some micro sources, such as fuel cell and micro turbine, storage device must be able to provide the amount of power required to balance $\mathrm{MG}$ following disturbances and/or significant load changes. Storage devices, such as flywheel and batteries, are modeled as constant DC voltage source using power electronic interfaces to be coupled with the electrical network. The storage device used in this paper is a flywheel and is connected to the VSI. The active and reactive power needed to balance generation and consumption inside the MG which injected to or absorbed from MG are proportional to frequency and voltage deviation (frequency and voltage droops).

\section{Control of the Two MGs Subsequent Islanding from the Main Grid}

In the presence of unplanned events like severe faults in the main grid as shown in Figure 1, MG separation from the main grid must occurs as fast as possible. If there are no synchronous machines to balance the demand and supply (as our case), the inverters must be responsible for frequency and voltage control during islanding operation. During connected mode (connected with main grid), all inverters can be operated in $P Q$ mode, in which voltage and frequency references (main grid) are available. In this case, a sudden disconnection from the main grid would lead to the loss of the MG, because load/generation balancing and therefore frequency and voltage control is not possible. However, by using a VSI connected

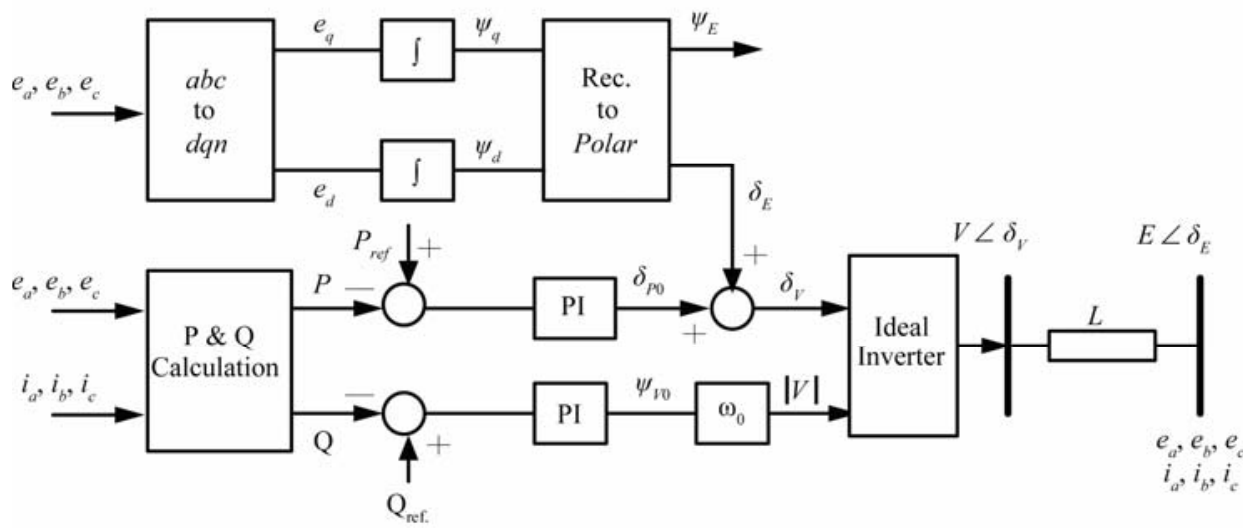

Figure 2. Basic structure of the $P Q$ inverter control scheme.

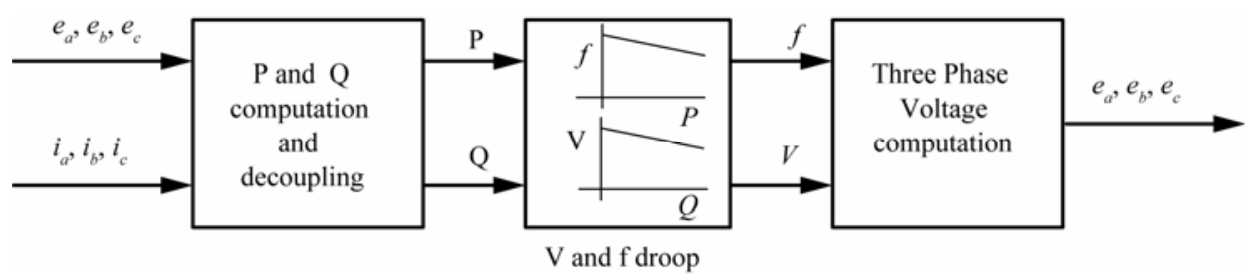

Figure 3. Voltage source inverter (VSI) control model. 
to the flywheel to provide a reference for voltage and frequency as explained in Equation (1), it thus possible to operate the MG in islanding mode.

\subsection{Two MGs Transfer to Islanding Mode and Separated from Each Other}

In this case there is no interconnection between the two MGs when islanding from main grid happens. During this situation, the voltage source inverter (VSI) connected to the flywheel is responsible for frequency and voltage control in each MG as described by Equation (1) and shown in Figure 4. However, those devices (flywheels) with high capabilities for injecting power during small time intervals have a finite storage capacity. Therefore, correcting permanent frequency deviations during any islanded operation conditions should then be considered as one of the key objectives for any control strategy. In order to promote adequate secondary control aiming to restore frequency to nominal value after disturbance, local frequency control by using a PI controller at each controllable micro source (SSMT and SOFC) is used to control active power outputs of the primary energy sources based on the frequency deviation error as shown in Figure 4. As indicated in Figure 4, the flywheel with its VSI acts as primary frequency control (acts as the inertia of synchronous machine in bulk power system) and the controllable micro sources (SSMT and SOFC) acts to balance the load and generation inside each MG. In addition, the VSI connected to the flywheel controls voltage of the MG (by controlling reactive power injected to or absorbed from MG) and acts like automatic voltage control in conventional bulk power plant as indicated in Figure 4.

\subsection{Two MGs Transfer to Islanding Mode and Connected to Each Other by a Private Line}

In this case, there is a private tie line connected the two MGs immediately subsequent islanding from main grid. The value of power flowing through the tie line depends on the difference between the two MGs frequencies $\left(\Delta f_{1}-\Delta f_{2}\right)$ as shown in Figure 5. Also, as discussed in case A, flywheel with its VSI will control voltage and frequency (primary frequency control beside voltage control) and controllable micro sources (SSMT and SOFC) acts as secondary frequency control as indicated by Figure 5. In this work, at the instant of islanding from main grid, the first MG has heavy loads and little generation, so that $\mathrm{MG}_{1}$ was imported certain amount of power (about 15 $\mathrm{kW}$ ) from the main grid before transfer to islanding mode, while the second MG has lightly loads and more generation which force $\mathrm{MG}_{2}$ to export some power to the main grid $(9 \mathrm{~kW})$ before islanding occurs.

\subsection{Two MGs Transferred to Islanding Mode and Connected to Each Other and Applied Automatic Generation Control upon Each MG}

This case is close to the second case in addition to frequency bias tie line control (discussed later) is applied inside each MG as shown in Figure 6. Frequency bias tie line controller will acts on the reference power of the controllable micro sources inside each MG (SSMT and SOFC) to correct the frequency deviation (return the frequency to its nominal value) and also back the tie line power to its scheduled value. In this study, the scheduled value of tie line power is zero. This means that the two MGs exchanges powers (active and reactive) during transient state only. After transient period finished, each MG will feeds its loads and the tie line power (active and reactive) returns to its value before transient occurrence.

\subsection{Frequency Bias Tie Line Control}

The basic objectives of frequency bias tie line control are to restore balance between each MG's loads and generations. This is met when the control action maintains:

- Frequency at the nominal value.

- Net interchange power with neighboring Microgrids at scheduled value.

The supplementary control (frequency bias tie line control) in a given MG should ideally correct only for changes in that MG. In other words, if there is a change in $\mathrm{MG}_{1}$ 's load, there should be supplementary control action only in $\mathrm{MG}_{1}$ and not in $\mathrm{MG}_{2}$ (after transient state finished). To execute that supplementary control inside each MG, a control signal made up of tie line flow deviations $\left(\Delta \mathrm{Ptie}_{12}\right)$ added to frequency deviation weighted by a bias factor would accomplish the desired objectives. This control signal is known as Area Control Error (ACE) in bulk conventional power system [16]. The same technique is used in our study for controlling the tie line power exchanges between the two MGs.

Based on above discussions, Area Control Error of $\mathrm{MG}_{1}\left(\mathrm{ACE}_{1}\right)$ is given by the following equations:

$$
A C E_{1}=\Delta P_{\text {tie12 }}+B_{1} \Delta f_{1}
$$

$B_{1}$ is the bias factor for $\mathrm{MG}_{1}$, and given by the following equation:

$$
B_{1}=K_{P 1}+D_{1}
$$

where, $K_{P 1}$ is frequency droop gain of $\mathrm{MG}_{1}$ given in equation (1) used for controlling flywheel installed in that MG. $D_{1}$ represents percentage of load change inside $\mathrm{MG}_{1}$ due to frequency deviation from its nominal value. 

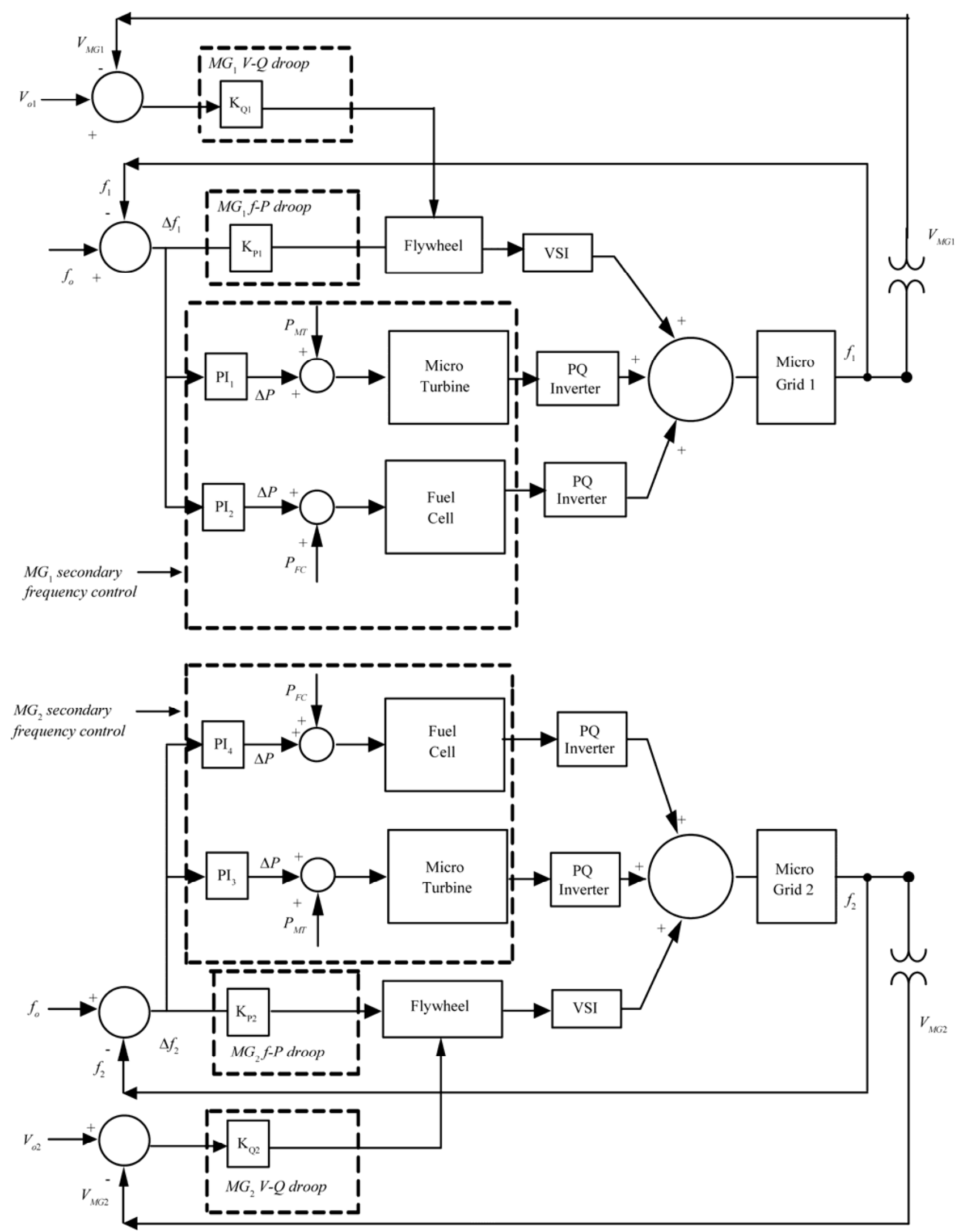

Figure 4. Control scheme of the two MGs (no private line connected the two MGs). 


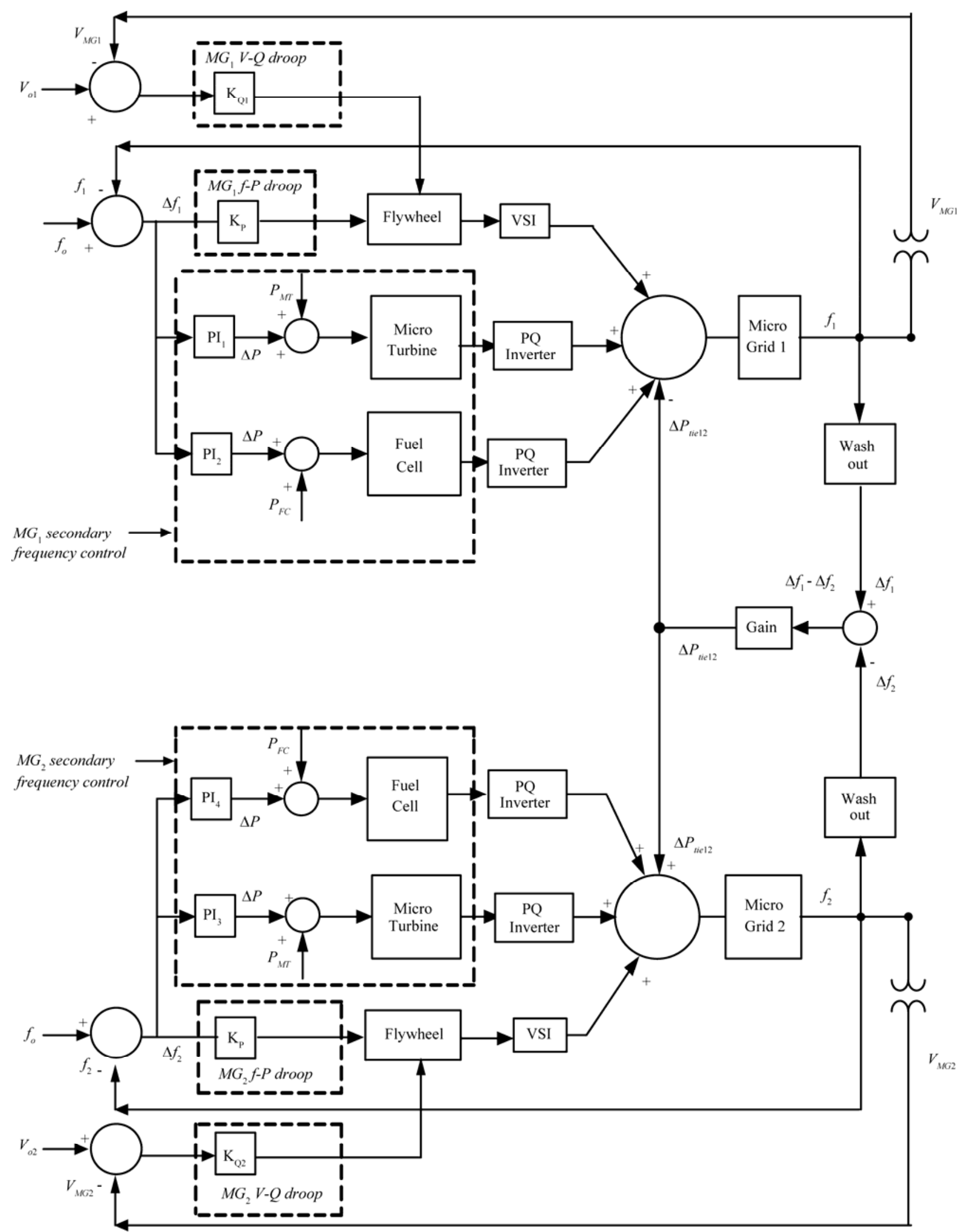

Figure 5. Control of two connected MGs without AGC. 


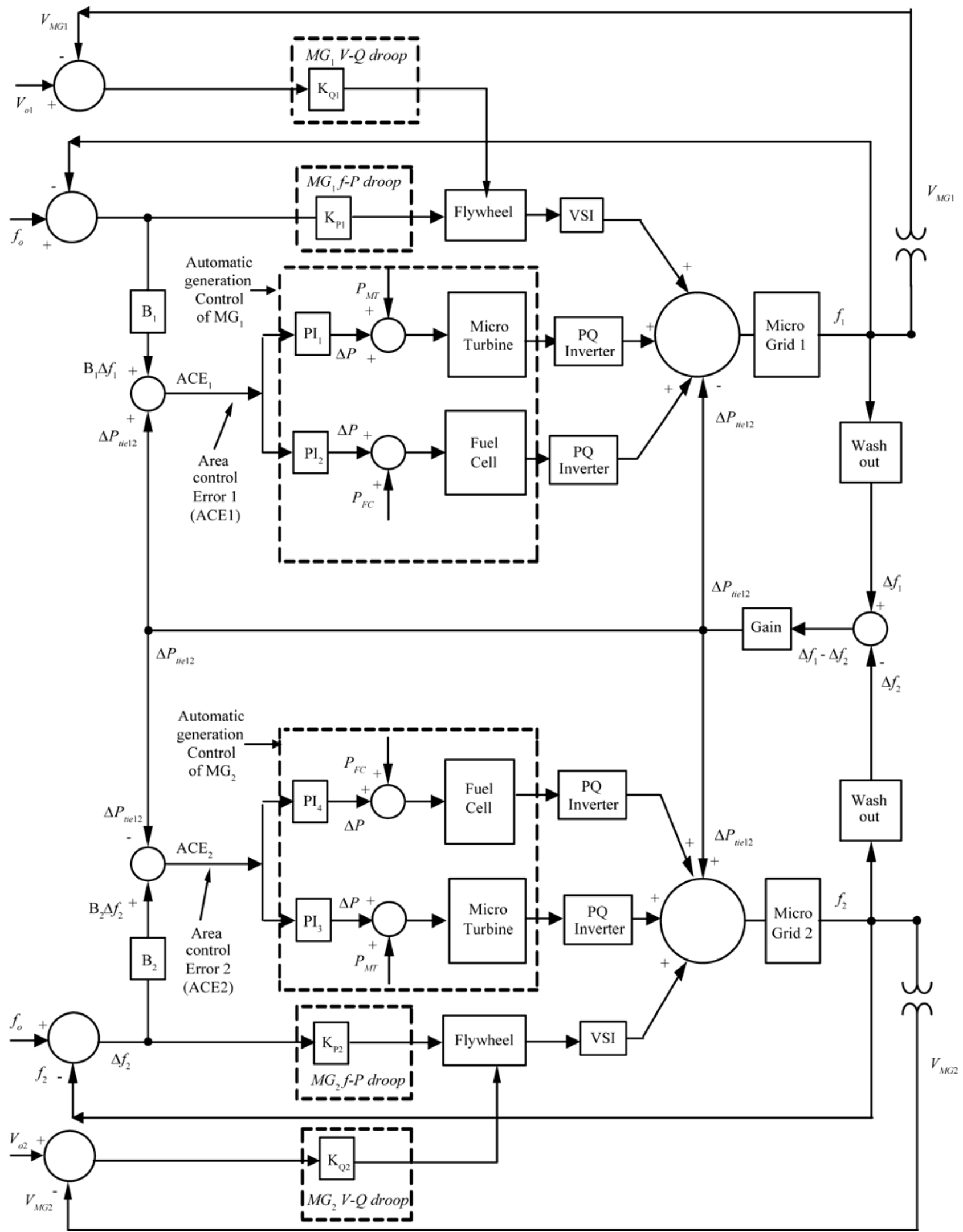

Figure 6. Control scheme of two connected MGs with AGC. 

by:

Similarly for $\mathrm{MG}_{2}$, Area Control Error $\left(\mathrm{ACE}_{2}\right)$ is given

$$
A C E_{2}=\Delta P_{t i e 21}+B_{2} \Delta f_{2}=-\Delta P_{t i e 12}+B_{2} \Delta f_{2}
$$

$B_{2}$ is the bias factor for $\mathrm{MG}_{2}$, and is given by the following equation:

$$
B_{2}=K_{P 2}+D_{2}
$$

where, $K_{P 2}$ is the frequency droop constant of $\mathrm{MG}_{2}$ used for controlling flywheel installed in that MG. and $D_{2}$ represents percentage of load variation in $\mathrm{MG}_{2}$ due to frequency deviation from the nominal value subsequent islanding occurrence from main grid.

$\mathrm{ACE}$ for each MG represents the required change in MG generation. The block diagram in Figure 6 illustrates how Automatic Generation Control (AGC) implemented inside each MG using ACE signal which applied to the reference power of the controllable micro sources installed inside each MG (SOFC and SSMT).

\section{Results and Discussions}

Disconnection from the upstream main grid was simulated in order to understand the dynamic behavior of each MG in the three studied cases. As we discussed before, SSMT and SOFC are supposed to be controllable micro sources used for secondary frequency control in the first two studied cases as shown in Figures $\mathbf{4}$ and 5, and used for AGC in third case as shown in Figure 6. In all three studied cases, wind speed and solar irradiance are assumed varying continuously. Wind speed and solar irradiance data are available in reference [4]. The simulation results are presented for the main quantities (Frequency, voltage, power, tie line power... etc).

From Figures 7-15, the following points can be summarized.

\subsection{For the First Case (Two MGs Separated)}

- Before islanding occurs, the two MGs are in their steady state. The frequency of the two MGs is at the nominal value $(50 \mathrm{~Hz})$. Any load change inside each MG can be compensated by the main grid and no need for secondary frequency control applied to the controllable micro sources inside each MG.

- When islanding occurred at $\mathrm{t}=60 \mathrm{sec}$., the two MGs islanded from main grid.

- For this studied case (no interconnection between the two MGs), each MG performs alone and the VSI connected to the flywheel in each MG acts to control the voltage and frequency of this MG.

- Frequency deviation in each MGs acts on reference power set points of controllable micro sources and try to adjust the generation and load inside each MG. Due to power deficit in $\mathrm{MG}_{1}$, frequency dropped to about $49.45 \mathrm{~Hz}$ as shown in Figure 7, while due to power surplus in $\mathrm{MG}_{2}$, frequency raised to about $50.15 \mathrm{~Hz}$ as shown in Figure 8 . Frequency deviation acts to increase the power of SSMT and SOFC of $\mathrm{MG}_{1}$, while it acts to decrease the power of SSMT and SOFC of $\mathrm{MG}_{2}$ as shown in Figures 12 and 13, respectively.

- The voltage of $\mathrm{MG}_{1}$ buses shows high drop (Figure 14) due to deficit of power (active and reactive), while voltage of $\mathrm{MG}_{2}$ buses shows small drop Figure 15 due to lost some reactive power which was supplied by the main grid before islanding.

- In order the two MGs can keep their stability subsequent islanding occurrence from the main grid, the flywheel of $\mathrm{MG}_{1}$ must inject about $15 \mathrm{~kW}$ and the flywheel of $\mathrm{MG}_{2}$ must absorb about $9 \mathrm{~kW}$ as shown in Figures 9 and 10, respectively.

- Controllable micro sources continue in adapting their generation until balance between load and generation inside each MG occurs (Figures 12 and 13) and the frequency of each MG back to its nominal value as shown in Figures 7 and 8 .

- Fluctuation of powers generated by the renewable source (wind turbine and photovoltaic panels) due to change of wind speed and solar irradiance cause fluctuations in the frequency of the two MGs Figures 7 and 8 and the VSI connected to the flywheel compensate those fluctuations (Figures 9 and 10) until the controllable micro sources can balance the load and generation inside each MG.

\subsection{For the Second Studied Case (Two MGs Connected with Each Other without AGC)}

- For this case, the two MGs have the same condition of the first case, but the two MGs connected with each other subsequent islanding occurrence from the main grid. In this case due to existence of the tie line between the two MGs, power surplus in $\mathrm{MG}_{2}$ will support the power deficit in $\mathrm{MG}_{1}$ and the frequency deviation of the two MGs shows small deviation compared with the first case. As shown in Figure 7, frequency $f_{1}$ dropped only to $49.93 \mathrm{~Hz}$ compared with $49.75 \mathrm{~Hz}$ in the first case, while the frequency $f_{2}$ will drop to about $49.93 \mathrm{~Hz}$ compared with $50.15 \mathrm{~Hz}$ in the first case as shown in Figure 8.

- Amount of active power required to be injected by flywheel of $\mathrm{MG}_{1}$ about $4 \mathrm{~kW}$ compared with 15 $\mathrm{kW}$ in the first case (Figure 9), while the active power required from flywheel of $\mathrm{MG}_{2}$ about $3 \mathrm{~kW}$ compared with $-9 \mathrm{~kW}$ in the first case (Figure 10). This means that when the two MGs connected with each other following islanding occurrence, the rating 


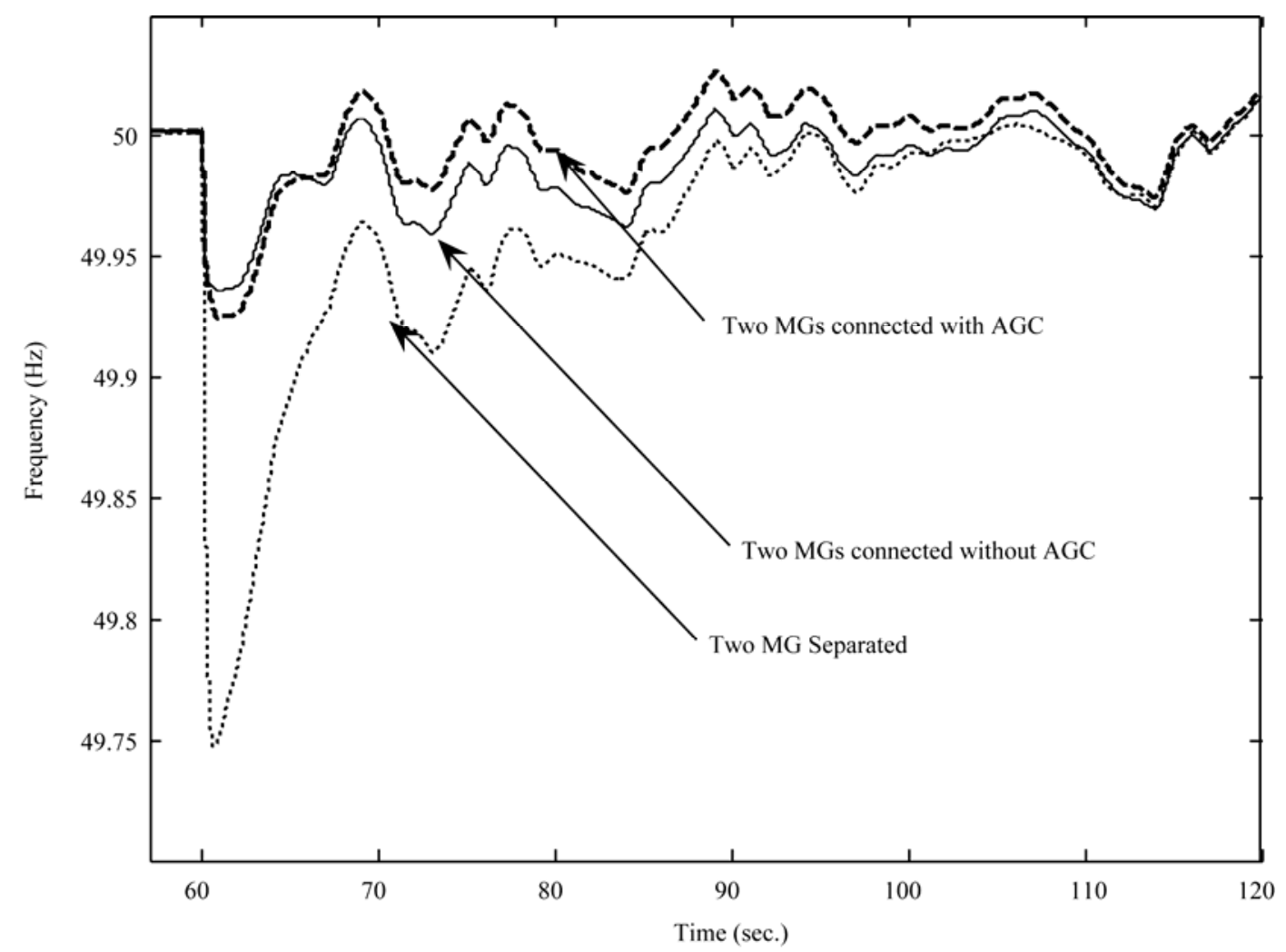

Figure 7. Frequency of $\mathbf{M G}_{1}$ for the three proposed controller schemes.

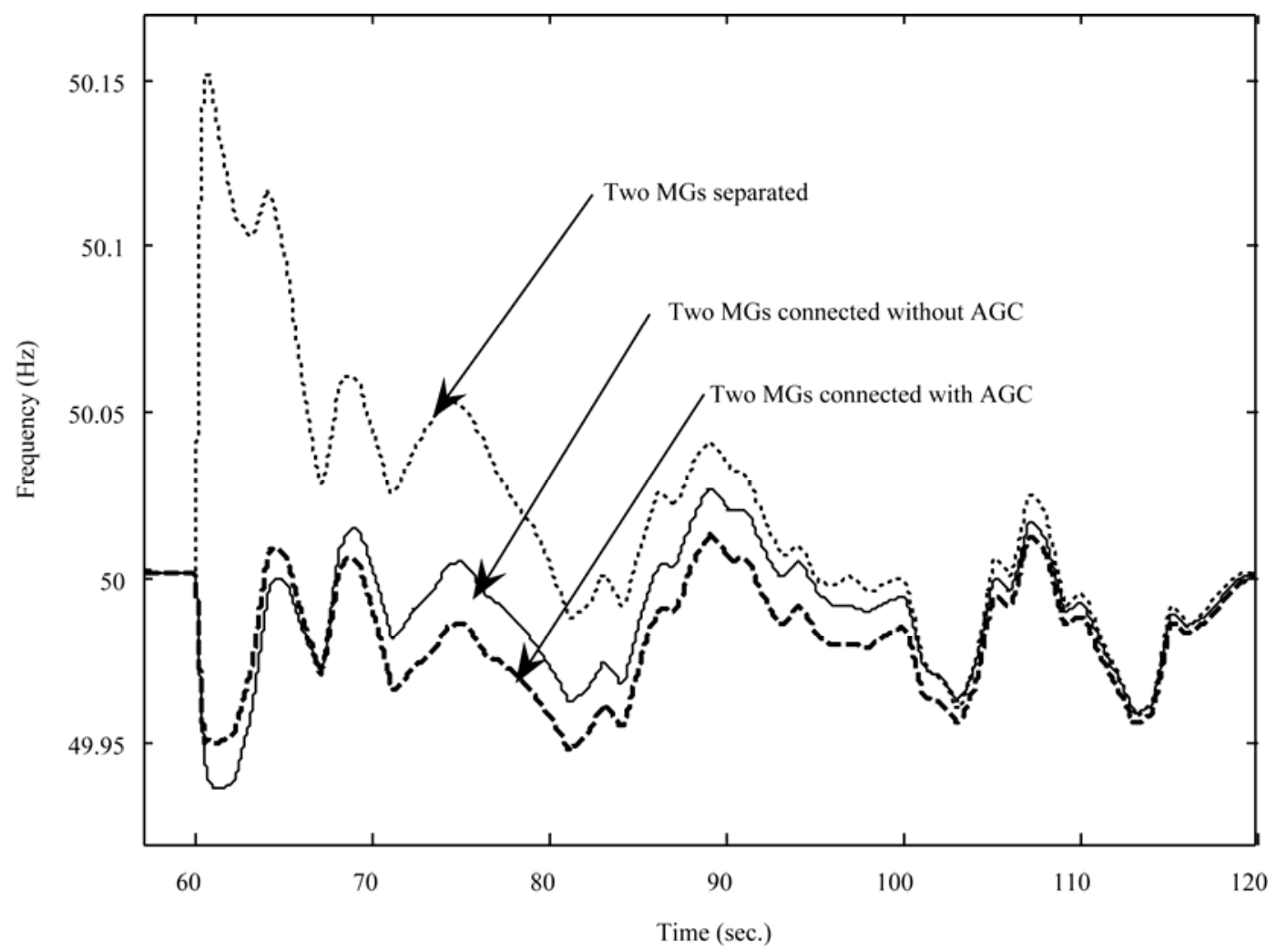

Figure 8. Frequency of $\mathrm{MG}_{2}$ for the three proposed controller schemes. 


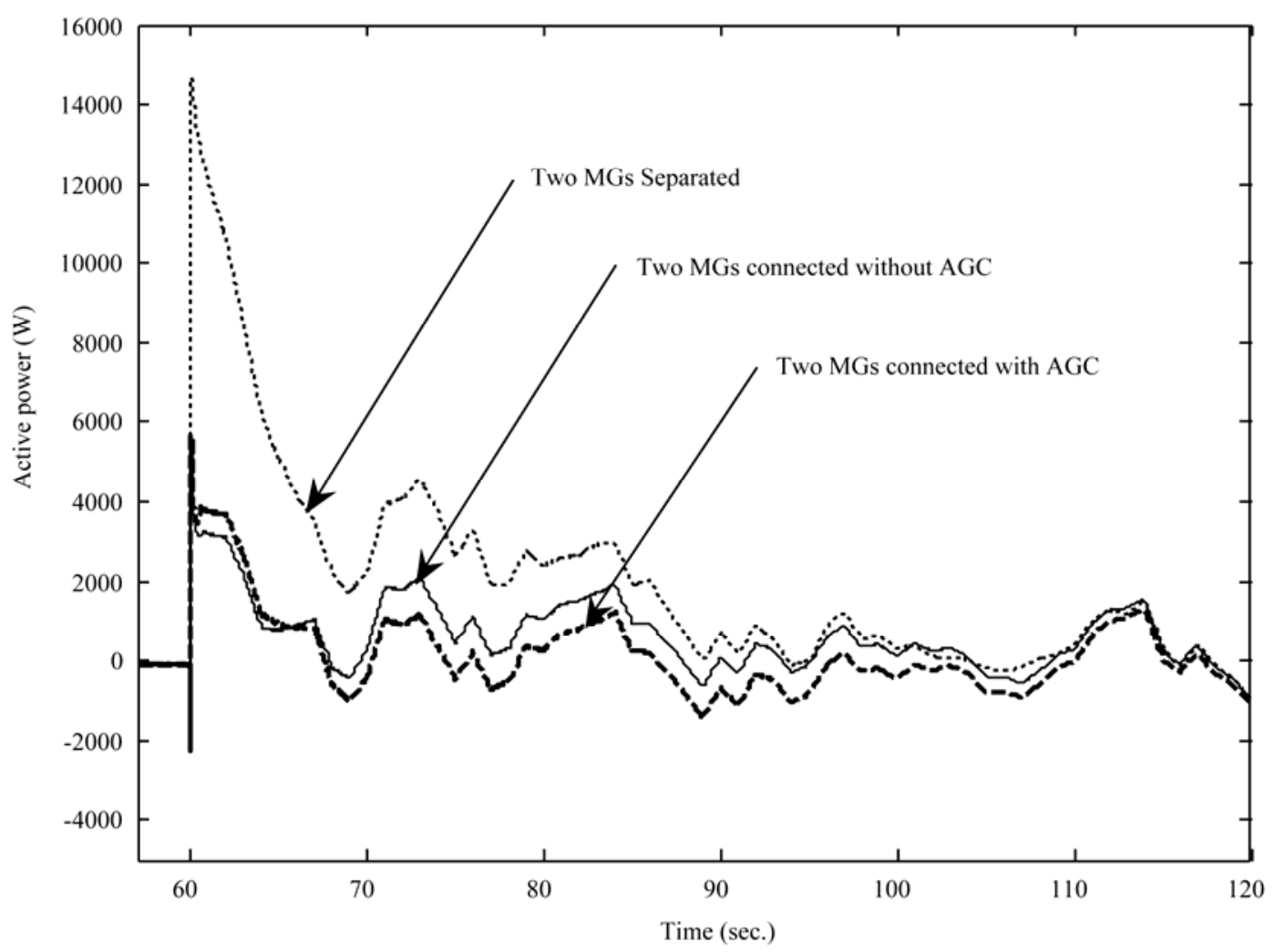

Figure 9. Active power injected by VSI connected to flywheel of $\mathbf{M G}_{\mathbf{1}}$.

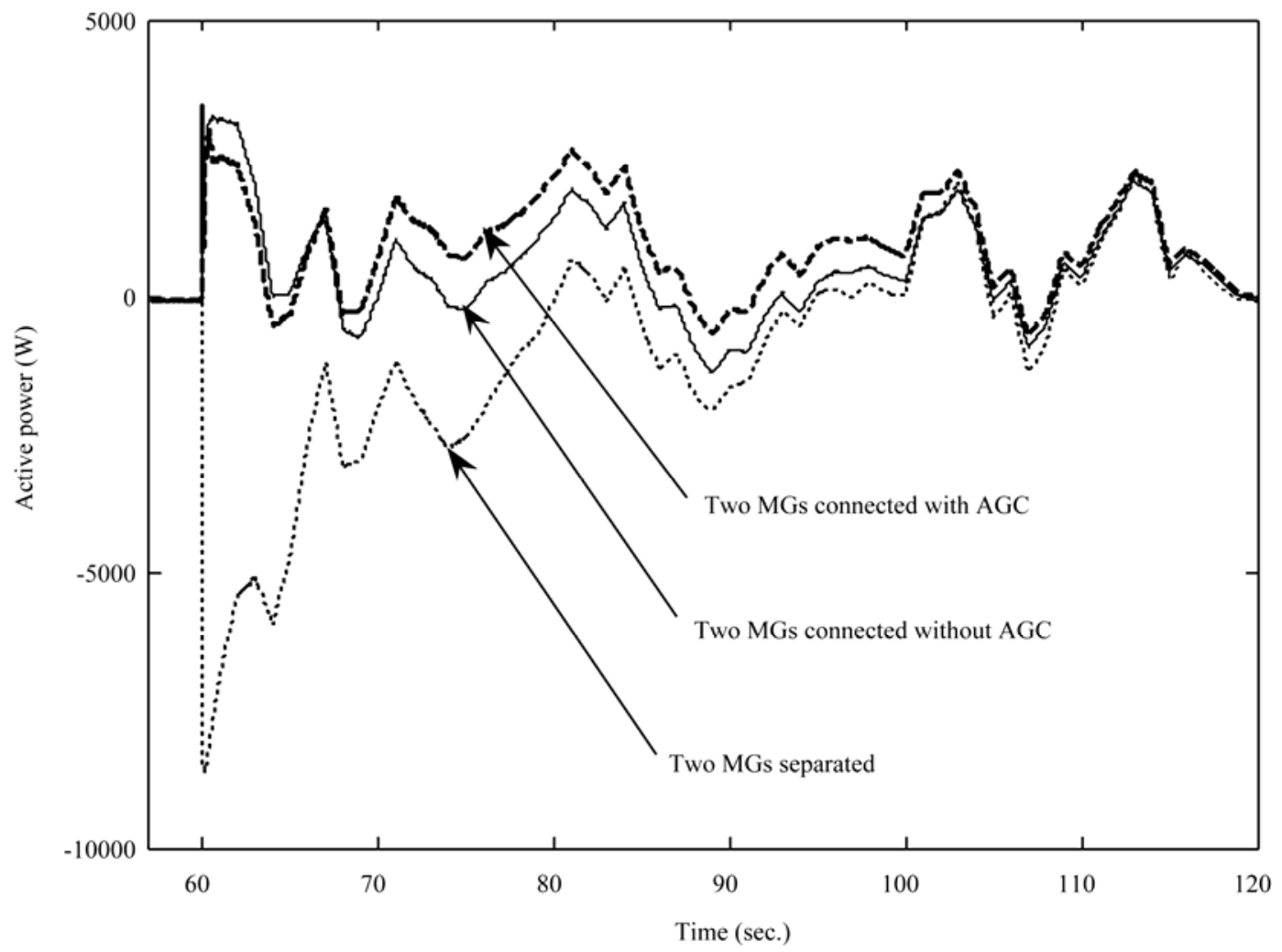

Figure 10. Active power injected by VSI connected to flywheel of $\mathbf{M G}_{2}$. 


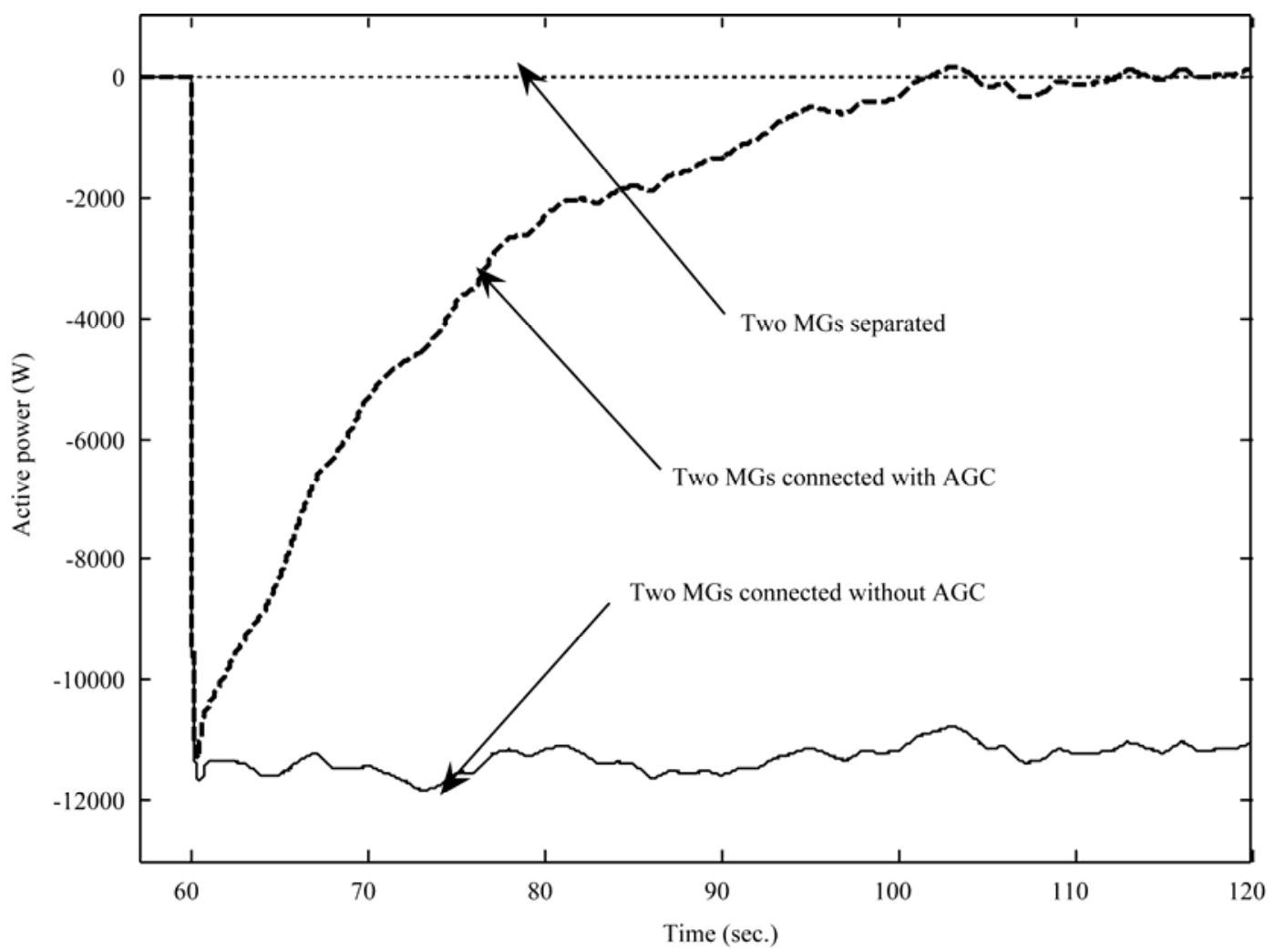

Figure 11. Tie line active power exchanges between the two MGs $\left(\Delta \mathrm{Ptie}_{12}\right)$.

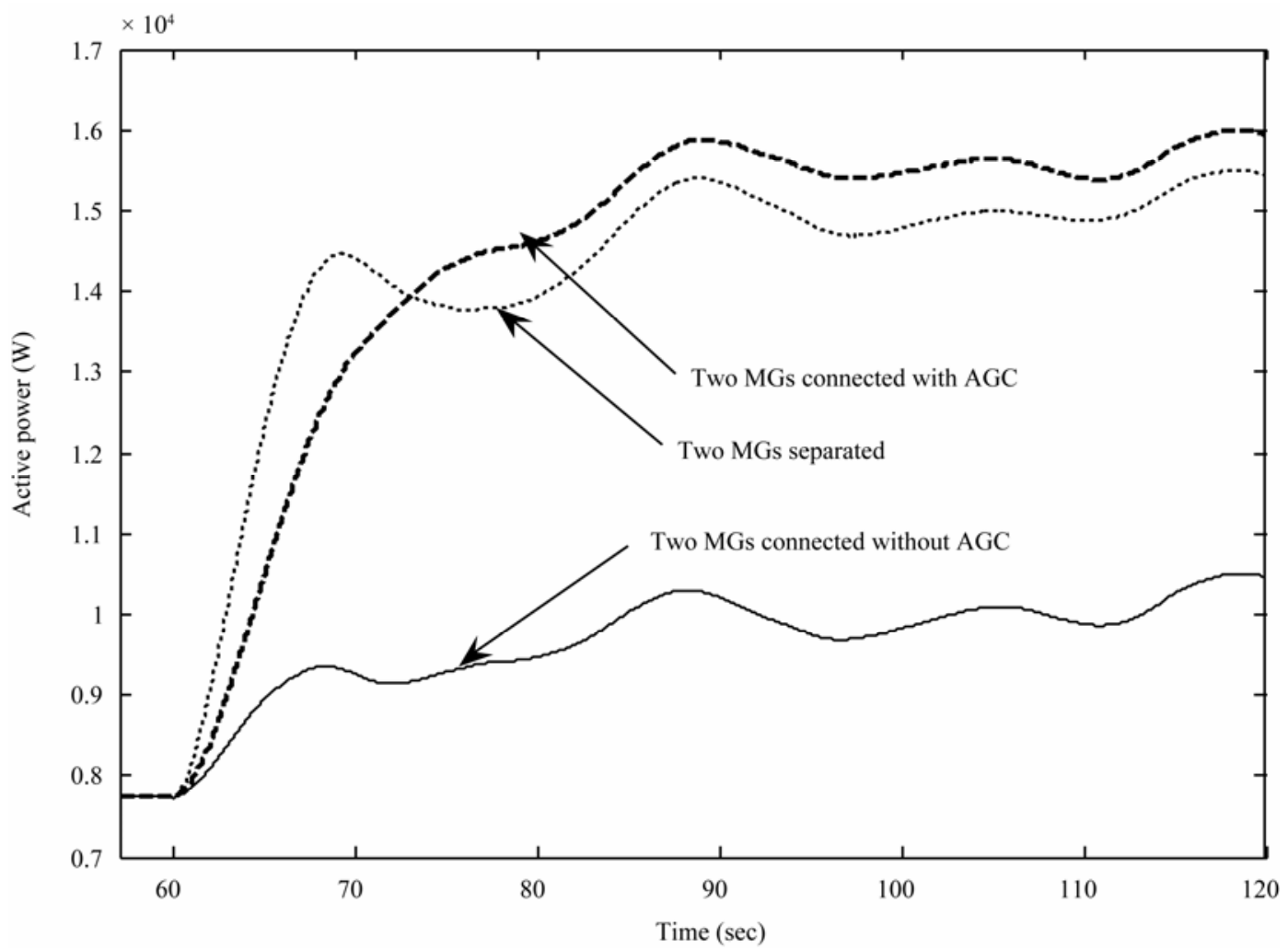

Figure 12. Active power injected by SSMT installed in $\mathbf{M G}_{1}$. 


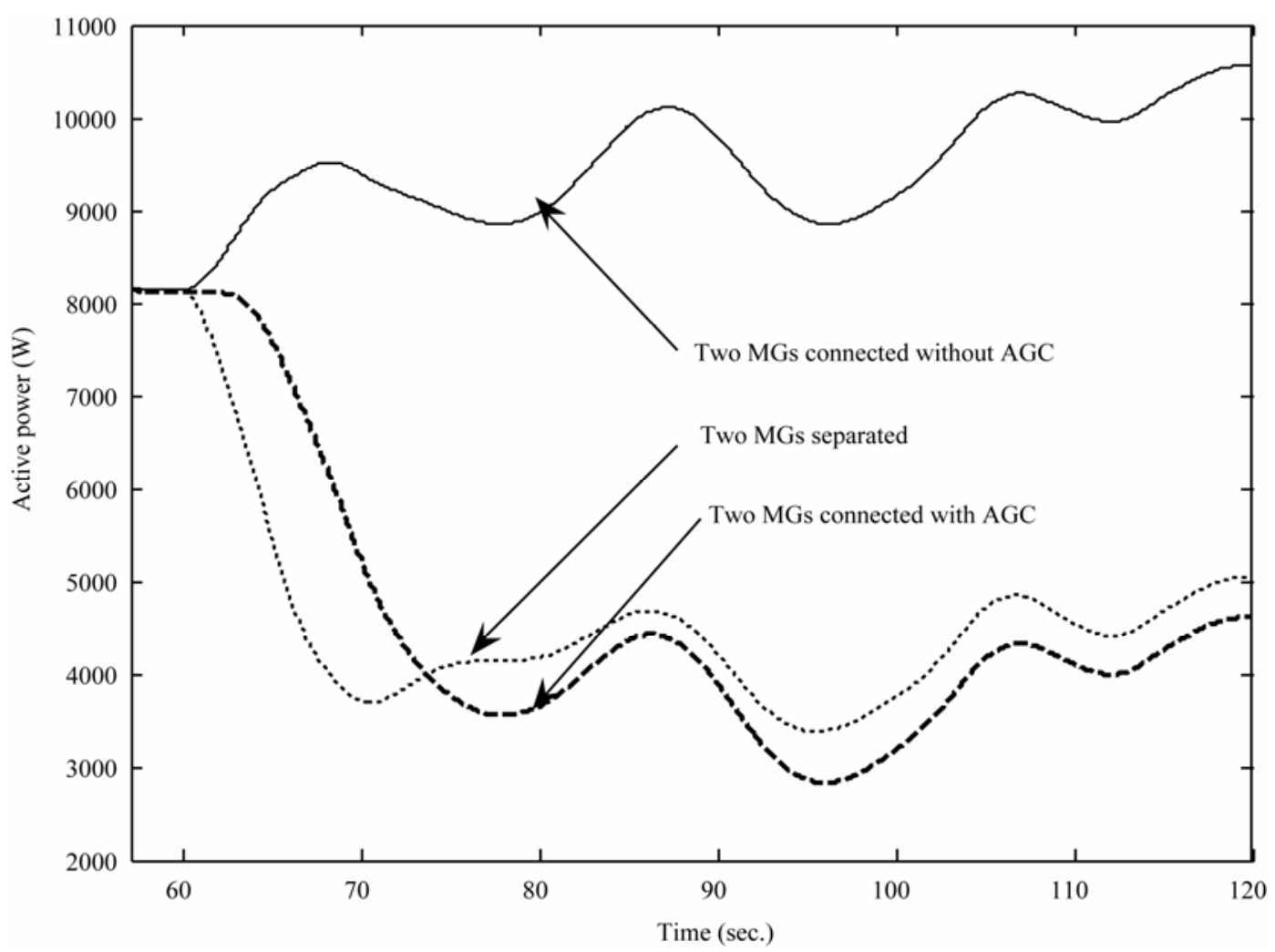

Figure 13. Active power injected by SSMT installed in $\mathrm{MG}_{2}$.

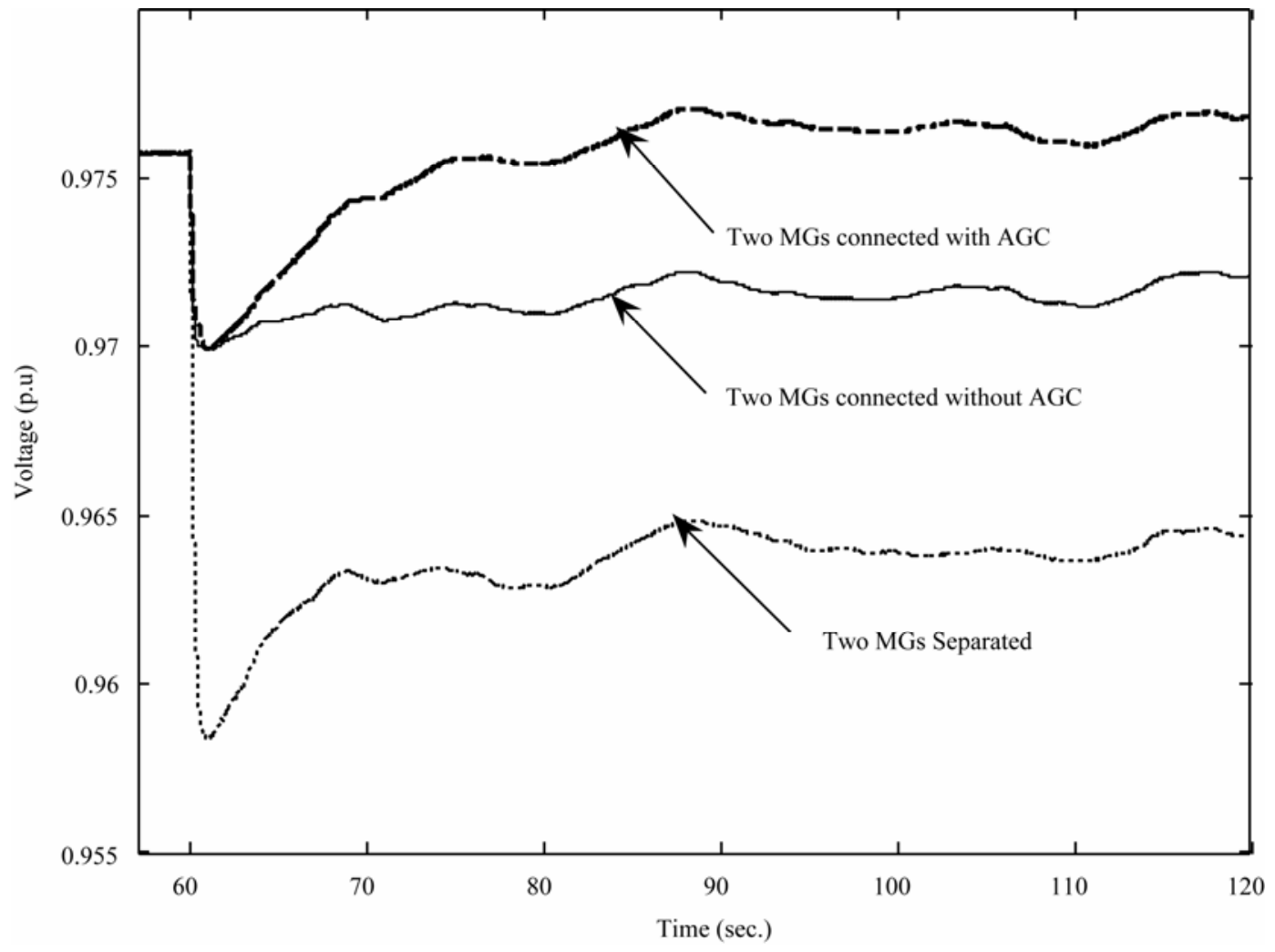

Figure 14. Voltage at bus \# 6 of $M_{1}$. 


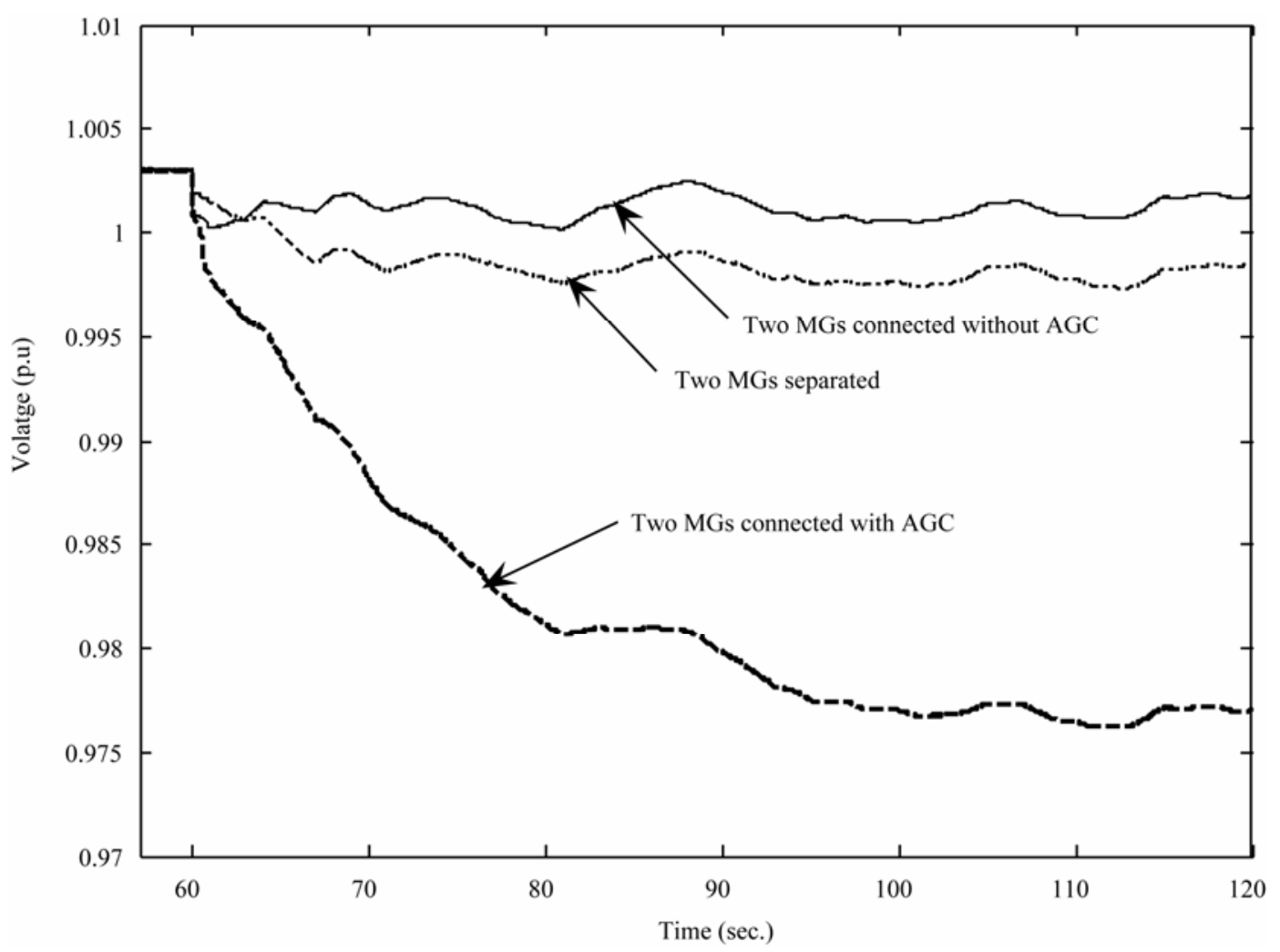

Figure 15. Voltage at bus \#6 of $\mathrm{MG}_{2}$.

of the required storage devices (flywheels) and accompanied inverters (VSI) is small compared with separated MGs.

- Voltage of $\mathrm{MG}_{1}$ has less drop (0.97 p.u) in the second case compared with the first case $(0.955$ p.u $)$ due to power (active and reactive) flows from $\mathrm{MG}_{2}$ through the tie line.

- As shown in the Figures 7-15, the dynamic response of the two MGs can be highly improved if the nearby MGs installed in the same distribution network are connected with each other by a private line subsequent islanding occurrence from main grid. Also, this interconnection between the adjacent MGs will be very important if one dominant micro source fails inside any MGs. For instance, if VSI accompanied with flywheel fails in any MG (after islanding from main grid), that MG will transfer to blackout unless the interconnection between the MGs exist. Also, this interconnection between the nearby MGs may be very useful if the controllable micro sources inside any MG reached their nominal power and can not produced any additional power. During those conditions, interconnection between adjacent MGs is necessary to keep the stability of the heavy loaded MG and keeps it far from blackout.

\subsection{For Third Case (Two MGs Connected with Each Other with AGC)}

- This case has performance almost close to the performance of the second case, however, AGC inside each MG acts on controllable micro sources to return the tie line power to its scheduled value (zero in our case) besides returns frequency to its nominal value as shown in Figures 7, 8, and $\mathbf{1 1 .}$

- For this case, voltage of $\mathrm{MG}_{2}$ is less than the two previous cases (Figure 15). This is because, when AGC applied in $\mathrm{MG}_{2}$, this $\mathrm{MG}$ must reduce its power (active and reactive) to return the tie line power to zero value. Reducing power generation inside $\mathrm{MG}_{2}$ leads to some drop in its voltages.

- Applying AGC inside each MG requires high rating of the controllable micro sources (Figure 12) to enable the MGs feed their loads locally and reduced the tie line power to zero as shown in Figure 11.

- AGC is necessary when contract between the owners of the two MGs states that the two MGs only support each other during transient state. After the transient state finished, each MG must feed its loads. In this case, tie line improved reliability and security of the two MGs. Also, reducing the tie line 
power to zero after the transient state finished, will reduce the losses inside the two MGs. This is because each MG feeds its loads locally and no power circulating from one $\mathrm{MG}$ to the other.

\section{Conclusions}

This paper dealt with improvement the dynamic response of the two nearby MGs when the two MGs connected through a private line subsequent islanding from the main grid occurs. It is noted from the results that the dynamic performance will gain high improvement by connected two nearby MGs. Frequency deviations is highly reduced. It is noted from the results that instead of the frequency of $\mathrm{MG}_{1}$ drops to $49.75 \mathrm{~Hz}$ without interconnection between the two MGs, it will only drop to 49.93 Hz. For $\mathrm{MG}_{2}$, frequency dropped to about $49.93 \mathrm{~Hz}$ instead of increasing to $50.15 \mathrm{~Hz}$. Also, amount of active power required to be injected by each flywheel highly reduced. AGC is applied to return the frequency of the two MGs to its nominal value and control the tie line power to its scheduled value according to the contract signed between the owners of the two MGs. Tie line connected the two MGs will be necessary in some emergencies situations like failure of a dominant micro source inside any $\mathrm{MG}$ or reaching the nominal power of controllable micro sources inside one of the MGs. Such conditions will force one of the MGs to blackout if tie line absent.

Finally we can conclude that connecting two nearby MGs with a private tie line when transfer to islanding mode from main grid is very effective method to increase the reliability and security of both MGs. Of course more improvement can be achieved if more nearby MGs connected with each others (three, four ...etc). Connecting more than MGs in islanding mode produces more strong MGs system when the MGs isolated from main grid due to large disturbance (fault) occurs in the main grid.

\section{REFERENCES}

[1] R. Strzelecki, "Power Electronic Control in Smart Electrical Networks," Springer-Verlag, London, 2008.

[2] R. Lasseter, et al., "White Paper on Integration of Distributed Energy Resources - The CERTS Micro Grid Concept," 2002. http://certs.lbl.gov/pdf/LBNL-50829.pdf

[3] N. Hatziargyriou, "MICROGRIDS-Large Scale Integration of Micro-Generation to Low Voltage Grids," EU contract ENK5-CT-2002-00610, Technical annex, May 2002. http://microgrids.power.ece.ntua.gr/
[4] J. Lopes, et al., "Defining Control Strategies for Micro Grids Islanded Operation," IEEE Transactions on Power Systems, Vol. 21, No. 2, May 2006, pp. 916-924.

[5] F. Kanellos, et al., "Micro-Grid Simulation during GridConnected and Islanded Modes of Operation," Interntional Conference on Power Systems Transients (IPST'05), Montereal, No. IPST05-113, June 19-23, 2005.

[6] S. Barsali, et al., "Control Techniques of Dispersed Generators to Improve the Continuity of Electricity Supply," Proceedings of Power Engineering Society Winter Meeting, Vol. 2, 2002, pp. 789-794.

[7] F. Katiraei, et al., "Micro-grid Autonomous Operation during and Subsequent to Islanding Process," IEEE Transactions on Power Delivery, Vol. 20, No. 1, January 2005, pp. 248-257.

[8] D. Georgakis, S. Papathanassiou, N. Hatziargyriou, A. Engler and C. Hardt, "Operation of a Prototype Microgrid System Based on Micro-sources Equipped with Fast acting Power Electronics Interfaces," Proceedings of IEEE Power Electronics Specialists Conference, Vol. 4, Aachen, 2004, pp. 2521-2526.

[9] T. Tran-Quoc, et al., "Dynamic Analysis of an Insulated Distribution Network," Proceedings of IEEE Power Systems Conference and Exposition, Vol. 2, October 10-13, 2004, pp. 815-821.

[10] R. Caldon and R. Turri, "Analysis of Dynamic Performance of Dispersed Generation connected through Inverters to Distribution Networks," Proceedings of 17th International Conference on Electricity Distribution (CIRED), Barcelona, No. 87, May 2003.

[11] R. M. Kamel and K. Nagasaka, "Design and Implementation of Various Inverter Controls to Interface Distributed Generators (DGs) in Micro Grids," Japan Society of Energy and Resources, Session 6.1, Tokyo, 2009, pp. 61-64.

[12] R. M. Kamel and K. Nagasaka, "Micro-Grid Dynamic Performance Subsequent to Islanding Process," Japan Society of Energy and Resources, Session 6.1, Tokyo, 2009, pp. 65-68.

[13] Y. Zhu and K. Tomsovic, "Development of Models for Analyzing the Load-following Performance of Microturbines and Fuel Cells," Electric Power Systems Research, Vol. 62, No. 1, May 2002, pp. 1-11.

[14] J. Padullés, G. W. Ault and J. R. McDonald, "An Integrated SOFC Plant Dynamic Model for Power Systems Simulation," Journal of Power Sources, Vol. 86, No. 1-2, March 2000, pp. 495- 500.

[15] N. Hatziagyriou, et al., "Modeling of Micro-sources for Security Studies," Proceedings of the CIGRÉ 2004 Conference, Paris, August 30-September 3, 2004.

[16] P. Kundur, "Power Systems Stability and Control," McGraw-Hill, New York, 1994. 